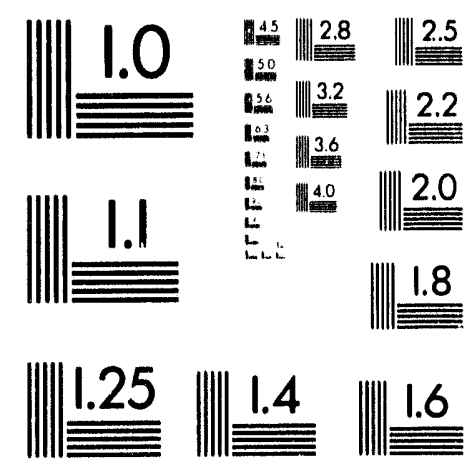



TITLE: Design and Analysis of High-Field Quasi-Continuous Magnets

AUTHOR(S): Heinrich J. Boenig, Laurence J. Campbel1, Dwight G. Rickel, John D. Rogers, Joe B. Schillig, James R. Sims

\section{SUBMITTED TO: Thirteenth International Conference on Magnet Technology}

\section{DISCLAIMER}

This report was prepared as an account of work sponsored by an agency of the United States Government. Neither the United States Government nor any agency thereof, nor any of their employees, makes any warranty, express or implied, or assumes any legal liability or responsibility for the accuracy, completeness, or usefulness of any information, apparatus, product, or process disclosed, or represents that its use would not infringe privately owned rights. Reference herein to any specific commercial product, process, or service by trade name, trademark, manufacturer, or otherwise does not necessarily constitute or imply its endorsement, recommendation, or favoring by the United States Government or any agency thereof. The views and opinions of authors expressed herein do not necessarily state or reflect those of the United States Government or any agency thereof.

\section{$\checkmark E I V E D$ \\ ОСТ 071993 \\ OSTI}

By acceptance of this article, the publisher recognizes that the US Government retains a nonexclusive, royalty-Iree license to publish or reproduce the published form of this contribution. or to allow others to do so, for US Government purposes

The Los Alamos National Laboratory requests that the publisher identily this arlicle as work performed under the auspices ol the U S. Department of Energy 


\title{
Design and Analysis of High-Field Quasi-Continuous Magnets
}

\author{
H. J. Boenig, L. J. Campbell, D. G. Rickel, J. D. Rogers, J. B. Schillig, J. R. Sims \\ National High Magnetic Field Laboratory (NHMFL), Los Alamos National Laboratory, \\ MS-E536, Los Alamos, NM 87545, USA. \\ P. Pernambuco-Wise, H. J. Schneider-Muntau, Luc Van Bockstal \\ NHMFL, 1800 E. Paul Dirac Drive B-223 \\ Tallahassee, FL 32306-3016, USA
}

\begin{abstract}
Pulsed magnets of 60 tesla or more with a flat-top of $100 \mathrm{~ms}$ (quasi-continuous) are among the user facilities to be provided by the NHMFL. The design of such magnets is constrained by avallable materials and thermal recycle time. The design path discussed here tallors materials and current densities of independent concentric colls. The progressive design steps are illustrated by a specific example of an eight-coll, 60'T magnet. In the prellminary design stage closed form calculations of magnetic, structural, thermal, and electrical circuit behavior are used to achleve a practical design that meets initial requirements. Design refinement incorporates finlte element analyses and test results on materials, fabrication and prototypes. Higher fields are possible without large changes.
\end{abstract}

\section{INTRODUCTION}

A new class of magnet, which we call 'quasi-continuous', is under development at several laboratories today. Intended for generic research, typically on materials in environments of very low temperature or high pressure, these pulsed magnets will maintain a field longer by an order of magnitude than traditional capacitor-driven pulsed magnets and will reach fields about twice as high as hybrids. The longer peak field period $(\approx 0.1 \mathrm{~s})$ and the impracticality of active cooling during the pulse indicate that a mass of a few tons is needed to absorb the ohmic heating. For convenient bore sizes the energy required is of order $100 \mathrm{MJ}$, which effectively rules out capacitor sources. The corresponding power would incur high demand charges from commercial utility grids, so mechanical energy accumulation and transfer using motor-generators becomes the most practical power source.

An ac power source has advantages for both the magnet designer and the ficld user. A fast response to detected faults can be made to effect orderly shut-down and protect equipment. Also, heating can be reduced by powering the magnet 'backwards' to shorten the pulse decay time. A wide range of pulse shapes can be provided to the user, including ramps, steps, and flat-tops. These advantages are improved by using independent power controls on a multi-coil magnet. A potential problem with ac power, shared by all continuous field resistive magnets, is ficld ripple. Active filtcring and/or compensation coils are possible solutions.

Quasi-continuous magnets will meet an important need within the research community for fields significantly higher

Manuscript submitted September 20, 1993. This work was supponed by National High Magnetic Field Laboratory and National Science Foundation, cooperative agreement No. DMR-9016241. than that of hybrids and significantly longer and more controllable than those of capacitor-driven magnets. Moreover, the experimental volume will be large enough to receive specialized apparatus including dilution refrigerators, diamond anvil cells, NMR probes, and magnetostriction cells. A flat-top field of $0.1 \mathrm{~s}$ will enable a large class of continuous field experiments to convert to pulsed fields, especially with the fast data recording and phase-lock instruments now available. The slower rise time of quasi-continuous fields also reduces eddy current heating and disequilibrium in the sample compared to capacitor magnets.

Quasi-continuous magnets are now recognized to be an important component of magnet research facilities and, consequently, are the object of intense design activity at several laboratories. Their ultimate development cannot be foreseen at this time in view of the advances occurring in high conductivity/high strength materials, reinforcement methods and materials, and design optimization.

Unlike capacitor-driven magnets, which are within the budget and capability of individual university researchers, quasi-continuous magnets are properly sited at national user facilities and are justified by the unique combination of pulse field strength, duration, and volume needed by researchers.

Issues relating to the design decisions of the NHMFL 60T magnet are discussed here. Other papers in these proceedings discuss prototype testing, materials, and the $400 \mathrm{MW}$ power supply for this magnet.

\section{DESIGN}

\section{A. Objectives}

The objectives for the NHMFL quasi-continuous magnet are

-produce a 60T flat-top pulse for $100 \mathrm{~ms}$;

- have a recycle time of approximately 1 hour;

-provide a $77 \mathrm{~K}$ borc of $32 \mathrm{~mm}$;

- have field homogeneity of 0.001 within a $10 \mathrm{~mm}$ sphere;

-be robust and reliable, with a lifetime of 10 years or 10,000 pulses;

-permit higher field upgrades as better conductors or reinforcements become available.

These objectives were chosen to be a balance between users' needs as known from experience with other magnets and what is estimated to be prudent and feasible for the first quasi-continuous magnet.

The flat-top requirement is merely used as a standard pulse. In actual operation a flat-top pulse may be preferred less frequently than other shapes. 
The cool-down time is approximately inversely pro. portional to the cost of the operation and user convenience. It is sufficiently important to dictate design changes.

Originally, a bore diameter of $44 \mathrm{~mm}$ was chosen but this was reduced to $32 \mathrm{~mm}$ to bu compatible with the NHMFL hybrid magnet bore and to reduce power supply costs.

Reliability is clearly a desirable attribute for a user facility, not only for safety (which must be assured even in the event of magnet failure) but to prevent damage to associated equipment and avoid disruption to busy user schedules.

\section{B. Approach}

The pulse length calls for a large conductor mass to absorb the ohmic heat, while the short thermal cycle time implies a large surface area for liquid nitrogen cooling. (Other cryogens, such a liquid argon, are eliminated due to cost and complexity.) The desirability of upgrades, as opposed to total magnet replacement, suggests a modular magnet design, which is also compatible with robustness because coil failure might be confined to a subsection of the magnet.

All these considerations led to the design concept of several mechanically independent and spatially separated coils with external reinforcing sleeves. This permits both the current distribution and the reinforcement thicknesses to be tailored for stress containment.

The 10-year lifetime requirement need apply only to the outer coils because periodic upgrades should occur more frequently with the inner coils, which are relatively small and inexpensive. It will be sufficient for their lifetime to exceed 1000 pulses. A feasible upgrade path would employ a stronger conductor to substitute conductor turns for reinforcement thickness in one or more inner coils.

The disadvantage of this approach is the reduced effective packing fraction and the associated high power needed. However, this problem is solved at Los Alamos by a motorgenerator which can supply $600 \mathrm{MJ}$ in less than a second, more than sufficient to power the 60T magnet.

To permit early closure on a specific design and, therefore, early delivery of the magnet, it was decided to give priority to conductor and reinforcement materials now commercially available, and to rely on the NHMFL materials program and developments elsewhere to enable upgrades. Materials tests have confirmed that GlidCop-60, a dispersion strengthened copper alloy manufactured by SCM Metal Products, Inc., is an adequate conductor for the $60 \mathrm{~T}$ magnet. A related alloy, GlidCop-15, has better conductivity and somewhat less strength. Further testing (of fatigue properties, in particular) of the GlidCop and reinforcing materials at both Los Alamos and Tallahassee confirmed this decision. A stainless steel (Fe$21 \mathrm{Cr}-6 \mathrm{Ni}-9 \mathrm{Mn}$ ) with the trade name Nitronic -40 was chosen for the reinforcing shells because of its low temperature strength and large elongation.

It was also decided to stay within the clastic limits of the conductor (following training) at every point of the magnet. This decision resulted in a more massive magnet and a larger power supply but a more robust design.

\section{ANALYSIS}

\section{A. Preliminary}

The analysis procecded through iteration by calculating the electrical behavior (throughout a pulse) and the mechanical stress induced at maximum field. The close interplay of these results led to a design having eight mechanically independent coils with external reinforcing sleeves of varying thickness. The coils are grouped electrically into three sets having independent power supplies. Fast cooling is achieved by separating the coils 3 to $4 \mathrm{~mm}$.

At this stage of the analysis fast results from frequent design changes were more important than high accuracy. This was accomplished with the method of Lontai and Marston [1]. Also the results of Markiewicz et al were useful for estimating the amount of axial stress transferred to the reinforcing shells [2].

As the design matured it became desirable to verify the approximate analysis and to calculate more detailed features such as thermal pre-stress, non-linear stress-strain characteristics of the conductor and mechanical pre-stressing caused by yield during magnet training, combined effects of thermal and electrical stresses over a pulse cycle, and cooldown characteristics of the conductor-epoxy composite. This led to finite element analysis.

\section{B. Finite Element Analysis}

The commercial, integrated, finite element analysis package COSMOS/M, version 1.65, (COSMOS/M is a registered trademark of Structural Research and Analysis Corp.) running on personal computers was used to model portions of the 60 tesla long pulse magnet. Magnetic fields, magnetic force loads on conductors, coil cooling, and nonlinear coil structural stresses and strains were calculated. Two dimensional axi-symmetric models, with quarter and half symmetry, of the entire magnet and individual coils have been generated using four-node quadrilateral elements. A combination of automatic and manual mesh generation was used to produce coarse and fine mesh models. To accurately model the magnetic ficld and force distribution a $2.44 \mathrm{~m}$ by $2.4 \mathrm{~m}$ region of space around the magnet was coarsely meshed; regions within the magnet representing individual magnet coils and supporting shells were finely meshed to allow for later fine-scale thermal and structural analyses of conductors, insulation and shells. After magnetic fields and magnetic conductor loads were calculated the elements representing empty space were discarded. The remaining elements were then redefined as required for thermal or structural analysis.

Finite element coil cooling analysis was performed using starting temperatures of coils, conductors and shells obtained from other circuit analysis and eddy current calculation software. These temperatures were input to the model along with thermal boundary conditions. Thermal calculations utilized material density, temperature dependent values of thermal conductivity and specific heat; temperature dependent orthotropic insulation thermal properties were used to accuratcly reflect the insulation's inliomogeneous structure. These thermal material properties were obtained from commercial vendors, the literature and from NHMFL sponsored material rescarch. 
A particularly valuable result of finite element cooling calculations showed that the coil with the largest radial dimension, coil eight, with its inner and outer radii held at 77 $\mathrm{K}$, would cool from $175 \mathrm{~K}$ to $90 \mathrm{~K}$ in about 2.3 hours. This was clearly too long and resulted in timely design modifications that increased axial cooling by exposing the middle windings to $\mathrm{LN}$ at both ends of the coil, thereby shortening the cool-down to about an hour.

Finite element structural analyses of coils included thermal and magnetic loading and calculated resulting linear and nonlinear elastic and plastic structural behavior. Mechanical and thermal loading were applied simultaneously. Material temperatures for input into the structural model were obtained from other circuit analysis and eddy current calculation software. Temperature dependent material mechanical properties (orthotropic in the case of the insulation) were utilized in the model. Commercial vendors, the literature and NHMFL sponsored materials research were the sources for this mechanical property information. Plastic behavior of the conductor was modeled assuming kinematic hardening. Coils were modeled through two complete load cycles. Conductor work hardening was calculated during the first cycle in the case of coil one with resultant permanent deformation and prestressing. Peak von Mises stresses (541 MPa) for coil one for the second cycle were lower than those for the first cycle (542 $\mathrm{MPa})$ demonstrating a slight pre-stressing. The results of finite element analysis completed thus far, appear to validate the 60 tesla, quasi-continuous magnet design.

Further finite element analysis of the magnet is indicated. Coils analyzed thus far show, after the cool-down portions of their load cycles, a high and probably unrealistic radial tensile stress at the interface between the coil and supporting shell. This stress is unrealistic in the sense that it may be higher the epoxy tensile bond strength between the coil and shell. This coil to shell bond may also be producing detrimental prestress in the coil and shell. The behavior of this coil/shell boundary can be clarified using gap-type friction finite elements that only allow the transmission of compression and shear loads when the boundaries they span are in contact. The COSMOS/M package contains gap-type friction elements in its element library and these may be used to model the interface and determine if it should be left unbonded by using a mold release compound on the inner surface of the shell during coil epoxy vacuum impregnation.

\section{RESULTS}

The results of the approximate analysis were largely confirmed by finite element analysis but sensitive issues involving thermal effects and local strains were highlighted.

The quarter-section is shown in Fig. 1 and a cross-section to scale is shown in Fig. 2.

Various mechanical, electrical and stress quantities are listed in Tables I, II, and III, respectively.

\section{UPGRADES}

As conductors with superior strength and/or conductivity become available the maximum field can be increased by replacing one or more of the coils, consistent with power supply capacity. This upgrade option is made more practicable by the modular design of both the magnet and the power supply. Because the power supply was generously sized to permit 60T operation within the elastic limits of Glidcop, an immediate upgrade to $65 \mathrm{~T}$ seems feasible by operating closer to the conductor's yield strength. Even higher fields are possible in smaller bores or for shorter pulse duration. Much depends on improved conductors, i.e., the relative improvements among conductivity, strength, and heat capacity. Among possible conductors, $\mathrm{CuAg}$, in particular, has promise for improvement through optimized processing.

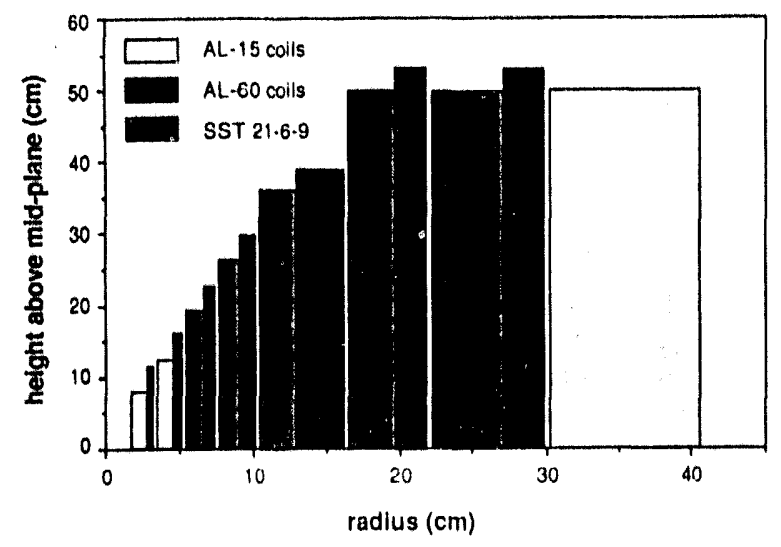

Fig. 1. Quarter-section of coils.

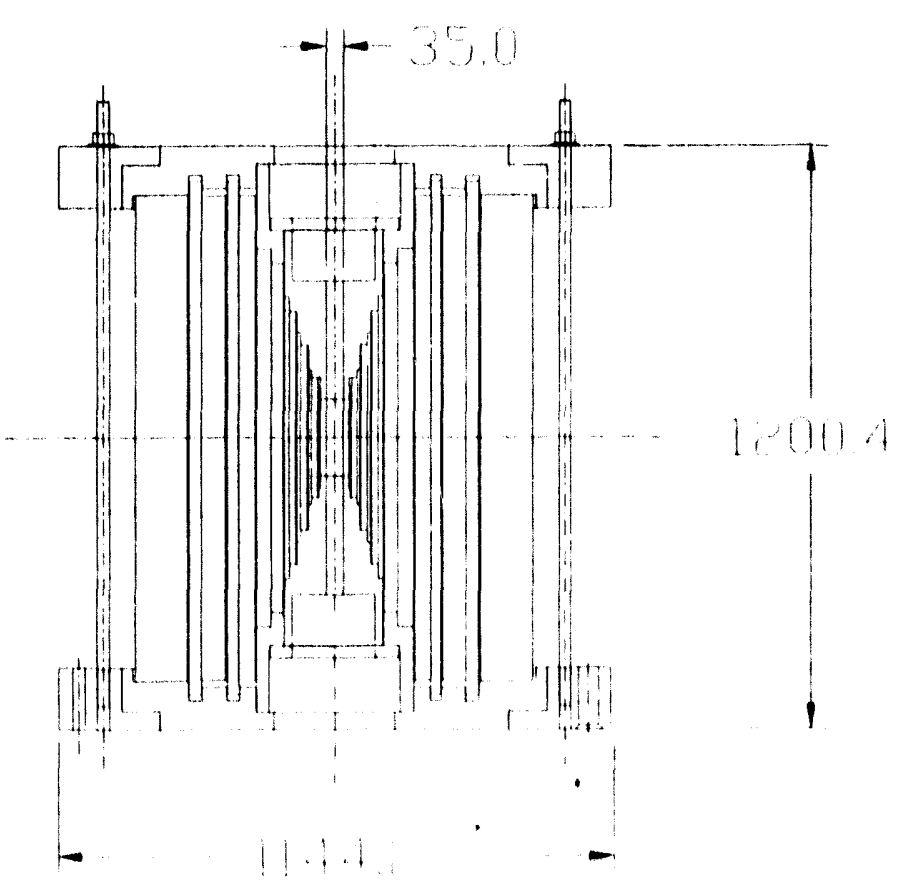

Fig.2. Cross-section of 8 coils and their mounting. The dimensions are in mm. 
TABLE I

MECHANICAL DATA

\begin{tabular}{llllc}
\hline coil & layers & $\begin{array}{l}\text { tums per } \\
\text { layer }\end{array}$ & $\begin{array}{l}\text { cond. hxw } \\
(\mathrm{mm})\end{array}$ & $\begin{array}{l}\text { shell thck. } \\
(\mathrm{mm})\end{array}$ \\
\hline 1 & 2 & 16 & $9.22 \times 4.33$ & 3.00 \\
2 & 2 & 25 & $9.22 \times 4.33$ & 5.90 \\
3 & 2 & 41 & $8.6 \times 5.2$ & 6.85 \\
4 & 2 & 56 & $8.6 \times 5.2$ & 9.65 \\
5 & 4 & 77 & $8.6 \times 5.2$ & 32.25 \\
6 & 4 & 85 & $11 . \times 6.7$ & 20.65 \\
7 & 6 & 85 & $11 . \times 6.7$ & 26.50 \\
8 & 12 & 74 & $12.5 \times 7.5$ & 0.0 \\
\hline
\end{tabular}

TABLE II

ELECTRICAL DATA

\begin{tabular}{lllll}
\hline coil & $\begin{array}{l}\text { cur. den. } \\
\left(\mathrm{kA} / \mathrm{cm}^{\wedge} 2\right)\end{array}$ & $\begin{array}{l}\text { field (T) } \\
\text { produced }\end{array}$ & $\begin{array}{l}\Omega-\text { start } \\
(\mathrm{mOhm})\end{array}$ & $\begin{array}{l}\Omega-\text { end } \\
(\mathrm{mOhm})\end{array}$ \\
\hline 1 & 47.56 & 4.5 & 0.48 & 1.71 \\
2 & 47.56 & 4.46 & 1.31 & 4.60 \\
3 & 42. & 4.76 & 3.61 & 10.73 \\
4 & 42. & 4.76 & 6.76 & 19.81 \\
5 & 42. & 9.51 & 25.71 & 73.72 \\
6 & 25.37 & 7.47 & 26.60 & 71.61 \\
7 & 25.37 & 10.69 & 54.28 & 140.30 \\
8 & 16.34 & 13.86 & 84.97 & 231.50 \\
\hline
\end{tabular}

TABLE III

STRESS DATA

\begin{tabular}{lllll}
\hline coil & $\begin{array}{l}\text { VM wndg } \\
\text { stress I } \\
(\mathrm{MPa})\end{array}$ & $\begin{array}{l}\text { rad. intrfc } \\
\text { pressure I } \\
(\mathrm{MPa})\end{array}$ & $\begin{array}{l}\text { rad. intrfe } \\
\text { pressure F } \\
(\mathrm{MPa})\end{array}$ & $\begin{array}{l}\text { VM shell } \\
\text { stress F } \\
(\mathrm{MPa})\end{array}$ \\
\hline 1 & 558 & 77 & 106 & 902 \\
2 & 608 & 112 & 135 & 980 \\
3 & 761 & 104 & 123 & 1093 \\
4 & 771 & 111 & 126 & 1117 \\
5 & 792 & 196 & 220 & 1020 \\
6 & 769 & 104 & 114 & 1112 \\
7 & 779 & 96 & 106 & 1105 \\
8 & 623 & - & - & - \\
\hline
\end{tabular}

\section{REFERENCES}

[1] L. M. Lontai and P. G. Marston, "A 100 Kilogauss QuasiContinuous Cryogenic Solenoid - Part l," Proc. Intern. Symp. Magnet Technology, 723, Stanford, 1965.

(2) W. D. Markiewicz. S. R. Voleti, N. Chandra, and F. S. Murray, "Transverse Stress on nb3Sn Conductors in High Field NMR Magnets," Proceedings of the Applied Superconductivity Conf., Chicago, 1992. 

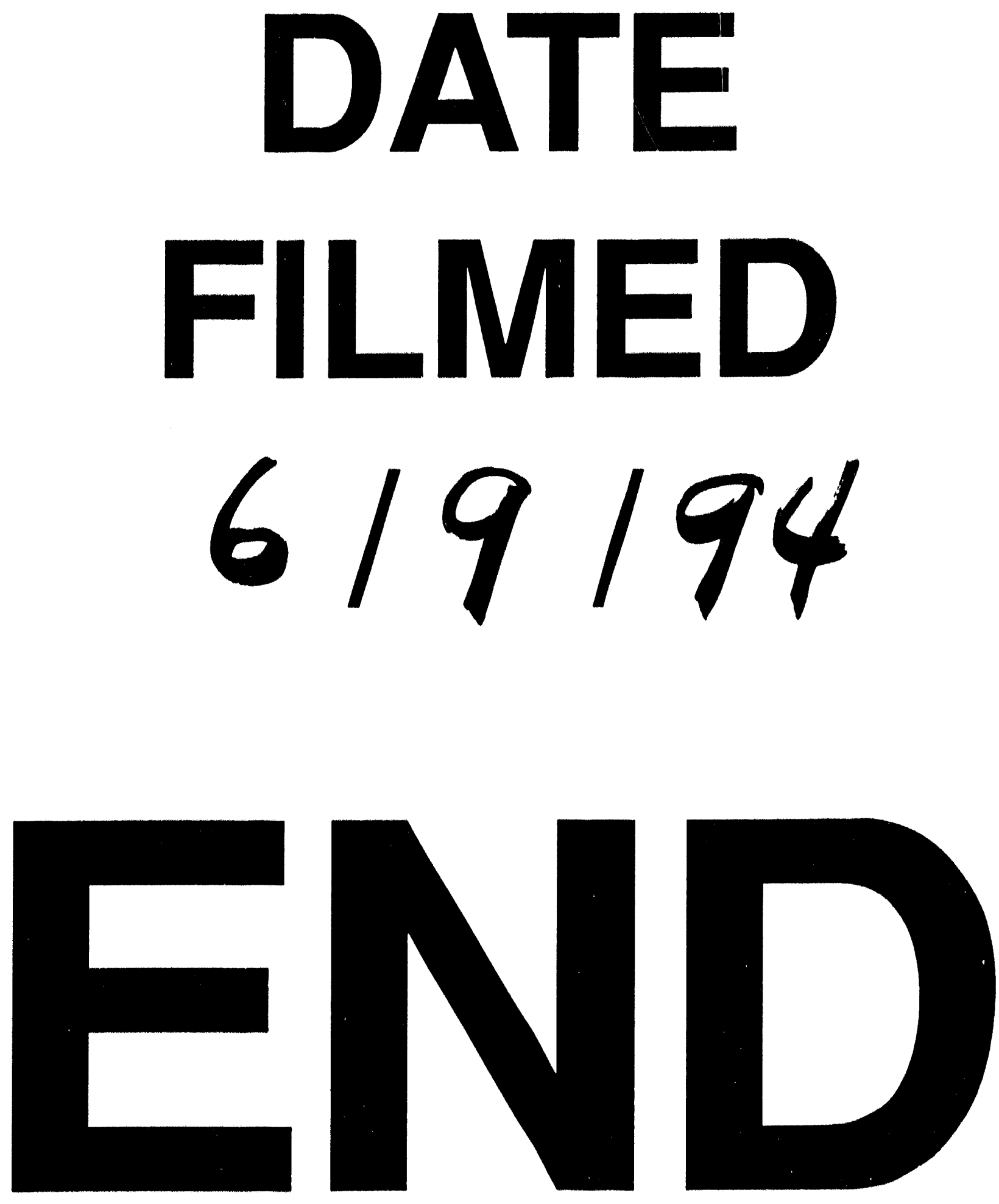


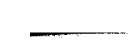
( 